\title{
Intestinal Parasite Survey of Kindergarten Ghildren in New Orleans
}

\author{
Daniel W. Hubbard, ${ }^{[45]}$ Patrick M. Morgan, Robert G. Yaeger, Walter G. Unglaub, \\ Marion W. Hood, and Righard A. Willis \\ Tulane University School of Public Health and Tropical Medicine, and Charity Hospital, New Orleans, Louisiana, USA
}

\begin{abstract}
Extract
A survey of intestinal helminths and protozoa was conducted on 887 5-year-old Negro kindergarten children from New Orleans public schools. Thirty-one percent of the children were found to be infected with one or more species of parasites. Nineteen percent harbored one or more species of medically important parasites. Seven pathogenic and four nonpathogenic species were identified.

\section{Speculation}

The prevalence of intestinal parasites in New Orleans kindergarten children was found to be high, although the average intensity of infection was found to be low. The prevalence of intestinal parasitism in the lower socioeconomic strata of the United States will continue to decline as living conditions and educational levels of this group are improved.
\end{abstract}

\section{Introduction}

The survey was conducted in conjunction with a nutritional evaluation and dietary intervention study in New Orleans kindergarten children initiated by the late Dr. Walter G. Unglaub in the fall of 1969. The study was undertaken after Operation Headstart research [34] and the Louisiana phase of the National Nutrition Survey [36] revealed nutritional problems as well as a large number of infections with intestinal parasites in New Orleans preschool children.

Surprisingly few recent reports on the prevalence of intestinal parasites in Louisiana and the United States were available at the time of this study. The prevalence of intestinal parasites in this country, however, was well documented earlier in this century. The largest survey was done by The Rockefeller Sanitary Commission, which reported a hookworm infection rate of 4.1.7\% among 577,000 persons in the South who were examined between 1910 and 1914. By 1930, when 424,-
000 more individuals were examined, the infection rate had declined to $19.3 \%$. Hookworm infections were found to be largely restricted to the warm, moist, sandy soil areas of the southern United States, whereas Ascaris lumbricoides has been found in most areas of the United States; the highest prevalence rates are reported to occur in the rural, mountainous areas of the middle eastern states. Surveys of these areas in the 1930 's revealed infection rates of 26.3 to $48.4 \%$ for Ascaris [8, 14-16, 28, 29]. A New Orleans study of urban ascariasis in 1936 showed a $6.6 \%$ infection rate [10]. Trichuris trichiura distribution has been found to closely parellel that of Ascaris, but usually with a lower prevalence. The 1930 surveys in Kentucky and Tennessee showed infection rates between $7 \%$ and $10 \%$ for Trichuris $[14,15,29]$. Enterobius vermicularis has been found to be as common in the northern as in the southern United States [19].

Surveys for intestinal protozoa in New Orleans in 
the 1920's and 1930's showed infection rates for Entamoeba histolytica to range from 3 to $8 \%$, whereas that for Entamoeba coli was approximately $10 \%$ or roughly double that of $E$. histolytica $[6,10,11,19,25,35]$. Craig [9] estimated that $10 \%$ was a conservative figure for the prevalence of $E$. histolytica in the United States at that time.

Several intestinal parasite surveys were reported in the late 1960's coincident with the increased concern over hunger and malnutrition in the United States and their possible relation to intestinal parasitism. These surveys confirmed the continued presence of intestinal parasitism in the United States. During the 1968-1969 national nutrition survey in Louisiana, 1,651 stool samples were examined from a random sample of low income persons of all ages from 19 parishes (counties) in the state [24]. Significant findings included infection rates of $5.3 \%$ for Ascaris and $12.3 \%$ for Trichuris. In 1970, Lease et al. [18] reported $48.1 \%$ of 180 Negro children from poverty stricken families in South Carolina to be infected with Ascaris and $51.9 \%$ of the same population to be infected with Trichuris. Martin in 1972 published the results of a comprehensive age- and race-specific intestinal helminth survey of Georgia [21]. Prevalence and worm burden data on 3,729 persons were reported from four geographical areas of the state. Overall prevalence rates were found to be $4.6 \%$ for hookworm, $1.3 \%$ for Ascaris, and $0.5 \%$ Trichuris; $12 \%$ hookworm and $3 \%$ Ascaris were found in the sandy, coastal regions.

Current estimates on the prevalence of pathogenic intestinal protozoa have been difficult to ascertain as reported data are not representative of the general population. The American Public Health Association gives the prevalence of $E$. histolytica as $1-5 \%$ in cities with good sanitation and the carrier rate for Giardia lamblia in the United States as between 1.5 and $20 \%$ [1]. Epidemic outbreaks of G. lamblia were reported in 1969 and again in 1970 [4, 23].

The general trend in the prevalence of intestinal parasitism in the United States has been downward for the past 30-40 years. Recent surveys, however, show that significant foci of infections persist in groups of individuals living under less than ideal conditions of personal and environmental sanitation. The percentage of infections varies greatly depending on where and how the parasitologic examinations are carried out; value of the data is generally restricted to the specific population group surveyed. One must expect to find highly local situations where primitive sanitary conditions exist and transmission of parasitic infec- tions readily occurs, especially in young children. Those surveys which record merely the presence or absence of parasites without regard to intensity of infection are of limited value in determining their effect on morbidity.

\section{Materials and Methods}

The sample population for the survey consisted of 887 kindergarten children from whom one or more stool samples were collected. The children attended 14 kindergarten classes in seven New Orleans Public schools which were located in predominately low income Negro neighborhoods. Stool examinations were performed under the auspices of the Tulane University School of Public Health and Tropical Medicine. The protocol for collection and examination of the stool samples was as follows.

1. Overall research protocol permitted stool collections at three intervals during the study. Stools were collected on successive classes of children at the beginning of the study in September 1969 and at 3 months and 6 months thereafter in conjunction with the clinical and biochemical examinations. Every effort was made to obtain specimens from those children who did not supply them initially.

2. Each child received a fecal collection cup labeled with name and identification number the day before scheduled clinics at the schools. Fecal cups were collected at the schools and delivered to the laboratory. The majority of the stools were of the formed variety and were from the morning evacuations of the children. Specimens were examined for helminth eggs and larvae and for protozoan cysts since examination was done on specimens held varying lengths of time wherein any trophozoites which might have been present would not be expected to survive.

3. Examinations consisted of microscopic examination of both direct saline smears and concentrates prepared by the zinc sulfate centrifugation and flotation method [12]. Individual and composite results from the three collection intervals were reported as well as the results of successive examinations on the same children (Tables I and II).

4. An egg count was made on smears which were positive for helminths. According to Beaver [38], the standard direct smear contains the equivalent of about $2 \mathrm{mg}$ formal feces and the counts should be reported as eggs per smear. Differentiation and confirmation of protozoan parasites were made with iron hematoxylinstained smears. The identification of hookworm species was not feasible in this study. 
Table $I$. Prevalence of intestinal helminths and protozoa, percent positive

\begin{tabular}{|c|c|c|c|c|}
\hline Parasite & $\begin{array}{l}\text { Exam } I, \\
712 \text {, } \\
\text { children }\end{array}$ & $\begin{array}{l}\text { Exam } I I, \\
\text { children }\end{array}$ & $\begin{array}{l}\text { Exam } I I I, \\
\text { cos } \\
\text { children }\end{array}$ & $\begin{array}{c}\text { Total, } \\
887 \\
\text { children }\end{array}$ \\
\hline \multicolumn{5}{|l|}{ Medically important } \\
\hline Ascaris lumbricoides & 2.38 & 1.23 & 0.49 & 2.25 \\
\hline Trichuris trichiura & 4.07 & 4.76 & 2.46 & 5.29 \\
\hline Enterobius vermicularis ${ }^{1}$ & 1.12 & 1.41 & 1.15 & 2.59 \\
\hline Hymenolepis diminuta & 0 & 0.17 & 0 & 0.11 \\
\hline Hookworm & 0.14 & 0.17 & 0 & 0.11 \\
\hline Giardia lamblia & 5.89 & 5.46 & 9.70 & 10.59 \\
\hline Entamoeba histolytica & 0.28 & 0.17 & 0.82 & 0.67 \\
\hline \multicolumn{5}{|l|}{ Medically unimportant } \\
\hline Entamoeba coli & 8.98 & 9.70 & 11.67 & 15.10 \\
\hline Endolimax nana & 1.96 & 2.64 & 5.92 & 5.86 \\
\hline Entamoeba hartmanni & 0.14 & 0 & 0.49 & 0.33 \\
\hline Chilomastix mesnili & 0.14 & 0.17 & 0 & 0.11 \\
\hline
\end{tabular}

${ }^{1}$ Diagnosed by means of stool examination.

5. Parasites were classified as to whether they were medically important or unimportant [12]. Medically important species found in this study were $A$. lumbricoides, T. trichiura, E. vermicularis, $H$. diminuta, hookworm, G. lamblia, and Entamoeba histolytica. Medically unimportant species included Entamoeba coli, Endolimax nana, Entamoeba hartmanni, and Chilomastix mesnili.

6. The numbers of light, moderate, and heavy infections of helminths were determined on the basis of the number of eggs found per standard direct smear. Using the standard direct smear, infections with egg counts of less than 40 Ascaris, 10 Trichuris, or 10 hookworm eggs/smear were classified as light. Those infections with counts of more than 200 Ascaris, 50 Trichuris, or 50 hookworm eggs/smear were classified as relatively heavy. Studies by Beaver and others show that egg counts made by direct smear correlate well with those made by more complicated dilution methods [2, 3, 20, 22]. Counts of the number of cysts per smear of medically important protozoa are not usually done because these may vary greatly from day to day and often do not correlate with symptomatology. Kotcher et al. [17], however, have graded Giardia infections 1 to 4 with the latter having over 50 cysts per high power field.

\section{Results}

Of the sample population of 887 children, $30.8 \%$ were infected with one or more species of intestinal parasites. One or more of the medically important species were found in $19.1 \%$. Seven medically important intes- tinal parasites were found in this survey (Table I). The composite prevalence rates were as follows: $A s$ caris, 2.3\%; Trichuris, 5.3\%; Enterobius, by stool examination, 2.6\%; H. diminuta, 0.1\%; hookworm, $0.1 \%$; Giardia, $10.6 \%$; and E. histolytica, $0.7 \%$. Three children had mixed infections of Ascaris and Trichuris; 2 had mixed infections of Ascaris and Giardia; one had a mixed infection of Ascaris and E. histolytica; 1 had a mixed infection with Trichuris and hookworm; 12 had mixed infections with Trichuris and Giardia; and 2 had mixed infections with Giardia and $E$. histolytica. The percentages of medically unimportant species found in the survey were: $E$. coli, $15.1 \%$; E. nana, 5.8\%; E. hartmanni, 0.3\%; and C. mesnili, $0.1 \%$.

Seven children were found to have heavy or moderately heavy helminthic infections. Two children had heavy Ascaris infections with 250 and 200 eggs/smear, respectively. Five children had moderately heavy $A s$ caris infections with $49,45,40,42$, and 68 eggs/smear, respectively. One child had moderately heavy Trichuris infection with 14 eggs/smear; this infection was in the same child with 250 Ascaris eggs/smear. All other helminthic infections were considered to be light. There were no differences in prevalence or type of infection recorded during the three samplings that could be related to the nutritional intervention study. In most instances the percentage of positive findings were higher when stools were examined more than once for each child (Table II). However, there was no consistent increase as one would expect if stools from each child were examined on consecutive days rather than at intervals of 3 months.

Table II. Prevalence of intestinal helminths and protozoa, percent positive by number of stools examined per child

\begin{tabular}{llcc}
\hline \multicolumn{1}{c}{ Parasite } & $\begin{array}{c}\text { 1 Stool, } \\
234 \\
\text { children }\end{array}$ & $\begin{array}{c}\text { 2 Stools, } \\
284 \\
\text { children }\end{array}$ & $\begin{array}{c}\text { 3 Stools, } \\
\text { children } \\
\text { chen }\end{array}$ \\
\cline { 1 - 2 } Medically important & & & \\
$\quad$ Ascaris lumbricoides & 2.56 & 3.16 & 1.35 \\
Trichuris trichiura & 5.55 & 6.33 & 4.06 \\
Enterobius vermicularis ${ }^{1}$ & 1.28 & 2.81 & 3.25 \\
Hymenolepis diminuta & 0 & 0.35 & 0 \\
Hookworm & 0 & 0 & 0.27 \\
Giardia lamblia & 6.41 & 13.38 & 10.84 \\
Entamoeba histolytica & 0 & 1.40 & 0.54 \\
Medically unimportant & & & \\
Entamoeba coli & 9.82 & 18.66 & 15.44 \\
Endolimax nana & 1.28 & 7.74 & 7.04 \\
Entamoeba hartmanni & 0 & 0.35 & 0.54 \\
Chilomastix mesnili & 0 & 0 & 0.27 \\
\hline
\end{tabular}

${ }^{1}$ Diagnosed by means of stool examination. 


\section{Discussion}

Recent intestinal parasite surveys in the United States which sampled low income groups have shown an environmental relation between intestinal parasitism and poverty. The prevalence of intestinal parasitism in poverty groups in the United States has not reflected the downward trends shown elsewhere. Owen and associates studied 585 preschool children in Mississippi and found that $25 \%$ of the children from those families with incomes under $\$ 500 /$ year were parasitized as compared with $10 \%$ of the children from families with incomes over $\$ 500 /$ year [30]. Lease and associates [18] surveyed 180 children from poor families in South Carolina and found $73 \%$ infected with Ascaris, Trichuris, or both. Of 1,651 persons from low income families in Louisiana studied in 1968 and 1969, 5.3\% were infected with Ascaris, $12.3 \%$ with Trichuris, $4.2 \%$ with $E$. histolytica, and $4.7 \%$ with Giardia [24]. Data from the present study show a sizeable reservoir of parasitic infections in New Orleans kindergarten children.

In comparison to disadvantaged groups in the developing countries, the prevalence of intestinal parasites in the United States has been found to be much lower. The Columbian Ministry of Health and Association of Medical Faculties examined 15,000 persons in 1965 and 1966 [7]. Of this number, 88\% were parasitized. Of those parasitized, $80 \%$ harbored medically important parasites. The more common infections were Ascaris, 53.8\%; Trichuris, 50.0\%; hookworm, 22.0\%; Strongyloides, 2.0\%; Enterobius, 5.9\%; and E. histolytica, 23.7. A similar survey of 515 persons of all ages among the urban working class population in Lagos, Nigeria revealed the following percentages of infection: Ascaris, 71.5\%; Trichuris, 66.6\%; hookworm, 58.3\%; Taenia spp., 2.1\%; Strongyloides, $11.7 \%$; Schistosoma spp., 0.4\%; and E. histolytica', 10.9\% [26]. No attempt was made to ascertain the impact of these infections on the populations health or nutritional status.

The records of Charity Hospital in New Orleans over a 30-year period offer a convenient comparison with the present survey [13]. Laboratory personnel examined 3,447 stool specimens in 1942 and 8,485 in 1972, respective positive findings were Ascaris, $4.2 \%$ versus $2.2 \%$; Trichuris, $7.5 \%$ versus $4.7 \%$; Enterobius by stool and cellophane tape methods, $1.4 \%$ versus $0.4 \%$; Strongyloides, $1.6 \%$ versus $0.4 \%$; Taenia, $0.2 \%$ versus $0.0 ; \%$ Hymenolepis nana, $0.02 \%$ versus $0.0 \%$; E. histolytica, $4.3 \%$ versus $0.5 \%$; $E$. coli, $9.3 \%$ versus $2.2 ; \%$ Giardia, $7.2 \%$ versus $2.4 \%$; $E$. nana, $8.2 \%$ versus $1.6 \%$; Dientomoeba fragilis, $0.2 \%$ versus $0.6 \%$; Trichomonas, $1.2 \%$ versus $0.2 \%$; Chilomastix, $0.2 \%$ versus $0.2 \%$; and Iodamoeba bütschlii, $0.6 \%$ versus $0.1 \%$. Percentages are based on total number of specimens examined from all age groups and are primarily from medically indigent persons in the greater New Orleans area. These figures show a decreased prevalence of E. histolytica, E. coli, E. nana, Giardia, hookworm, and Strongyloides, and continued low positive findings for Trichomonas, Iodamoeba, Chilomastix, Dientomoeba, Taenia, and H. nana. Ascaris and Trichuris show lower but still significant findings in this primarily urban population.

Results of the present study are comparable with Charity Hospital data with three exceptions. The kindergarten children had a higher prevalence of Giardia, ( $10.53 \%$ versus $1.96 \%)$, E. coli, (15.95\% versus $2.60 \%$ ), and Enterobius, (2.53\% versus $0.62 \%)$. This might be explained by the fact that the sample population consisted of 5-year-old children in whom the prevalence of fecally transmitted parasites and pinworms is usually higher. The prevalence of the amebic dysentery organism, E. histolytica, was consistent with that reported at Charity Hospital and reflects the gradual decline of prevalence rates in the United States.

The one case of hookworm disease found in the study was in a child whose family had recently emigrated from Honduras; three other members of the family were also infected. This aptly demonstrates that immigrants can bring parasitic diseases into the United States under existing health screening regulations for such persons.

The one case of rat tapeworm infection $(H$. diminuta) was interesting as only about 100 of these infections have been reported in the United States (12). Accidental infection of many by this animal parasite sometimes occurs when food supplies are contaminated with anthropods (rat flea larvae, beetles, etc.) carrying the cysticercoid form of the parasite [12].

Our study showed that although the prevalence of intestinal parasitism in New Orleans preschool children was relatively high, the worm burden or intensity of infection was rather low. Of the 887 children examined, only 7 of the 169 children with medically important parasites showed heavy or moderately heavy infections which might be expected to interfere with health or nutritional status when dietary intake is marginal. None of the infected children demonstrated overt clinical signs or symptoms of parasitism. No medical sig- 
nificance could be attached to the high rates of infection.

Beaver [38], in analyzing prevalence data on ascariasis, trichuriasis, and hookworm infections, observed there is also a close relation between socioeconomic status and the intensity of these infections. The most advanced communities and the most favored members within them are almost invariably the least frequently and least heavily parasitized. In considering the prevalence of infection among members of any socioeconomically advancing large community, Beaver stated that the reduction in the rate of infection in succsssive decades is directly proportional to the degree of socioeconomic advancement. These generalizations also hold true for disadvantaged groups within a highly advanced country such as the United States.

The reasoning of Schaefer and Johnson [33] may further explain why so few heavily parasitized children were found in the sample population in New Orleans. In reporting the preliminary results of the Ten State Nutrition Survey, they surmised that the general health of low income persons in the United States is better than those in poverty areas abroad because our population usually enjoys pure water, a safe food supply, excellent sewage disposal, and good medical care. They are not usually exposed to the stressful insults of a hostile and filthy environment frequently seen in the slum areas of developing countries. The availability of free medical care for the indigent population of New Orleans at Charity Hospital may be another factor in controlling the intensity of parasitic infections as well as the common custom of treating children for worms at home with medicine purchased from local pharmacies.

\section{Control and Eradication of Intestinal Parasites}

The eradication of intestinal parasites in the United States will be difficult to achieve. The present study and other surveys show that there is a significant reservoir of medically important parasites in the city of New Orleans, elsewhere in Louisiana, and in other areas of the United States. Although not proved to have a significant effect on the health status of the affected population, this reservoir of infection would be significant in the event of a manmade or natural disaster when normal controls over food, water, sewage, housing, and waste disposal are not in operation. A national plan to eradicate intestinal parasites in the United States does not exist. Disagreement prevails over the medical significance of intestinal parasites and the need for additional control measures in the United States. Foreign governments seem to be more concerned over the problem of intestinal parasites than does the United States. The greater intensities of infection and the relatively poor nutritional status of a large proportion of their populations may justify this concern. In Japan, for example, mass campaigns to eradicate helminths have resulted in a reduction of the prevalence rate from $62.9 \%$ in 1949 to $4.2 \%$ in 1966 [39].

Fras:r [37] has estimated that over one million persons in the southeastern United States are infected with intestinal parasites. In his opinion, control of ascariasis and trichuriasis in this country has not been undertaken because professionals disagree over the importance of these two infections and because requirements for an effective control program, sanitary facilities, health education, and medical treatment appear to be overwhelming. It is interesting to note that researchers at the University of South Carolina have recently received a federal grant of $\$ 200,000$ to attempt eradication of ascariasis and trichuriasis in South Carolina [27].

Beaver in his 1961 World Health Organization Monograph, "Control of Soil Transmitted Helminths," stated that the use of medicine in an attempt to eradicate Trichuris and hookworm infections had to await better drugs, whereas it is feasible to selectively eradicate ascariasis by the use of piperazine. More than 10 years later the same situation still exists. Broad spectrum anthelmintics for use in the United States have not been approved, although 2,2-dichlorovinyldimethylphosphate has been successfully fieldtested in Puerto Rico and Costa Rica [5, 31]. The drug was found to be safe and effective against Ascaris, Trichuris, and hookworms in both trials. A single dose of $12 \mathrm{mg} / \mathrm{kg}$ body wt eliminated $85 \%$ of the hookworm infections, $75 \%$ of the Ascaris infections, and $90 \%$ of the Trichuris infections. Further trials with a pediatric population are needed before recommendations for its use are warranted. A newer broad spectrum anthelmintic, mebendazole, has been successfully evaluated by Pena-Chavarria et al. [32] in Costa Rica.

Beaver [38] concluded that the control of intestinal helminths may be viewed as a stepwise procedure beginning with populations whose major health problems are related to such basic needs as food, housing, and sanitation, and ending when these needs are satisfied to the extent that transmission meets natural barriers. As basic individual and community needs are provided, both the transmission and the effect of the parasites diminish and eventually lose public health 
significance. Transitional stages when climate and soil conditions are highly favorable to transmission may pose enduring problems of intestinal parasitism and at times may be aggravated by social and economic maladjustments. A control program should aim at developing natural barriers to transmission and abating the adverse social and economic effects of the infections.

\section{Conclusions}

The overall prevalence of intestinal parasites in the sample population was found to be relatively high, whereas the intensity of infection was found to be low. The majority of children with medically important parasites had light helminthic or asymptomatic protozoan infections. Although parasitic infection was common among the children, the presence of clinically important disease was not. This is probably true of all regions of the United States where parasitic infections occur in important numbers. The presence of soiltransmitted and feces-transmitted parasites in the children is a reflection of the poor personal and environmental sanitary conditions under which they live. An increase in the prevalence of fecal borne parasites in children can be expected under crowded classroom. conditions.

There are no long range plans to eradicate intestinal parasites in the United States. Broad spectrum anthelmintics currently approved for veterinary usage are not approved for human treatment in the United States. Detection and treatment of diseased persons are more practical and far less costly than programs of eradication which are futile unless transmission of parasites is controlled.

Practical control measures for intestinal parasites in the United States, therefore, continues to be as follows.

1. There should be surveillance of high risk population groups within individual states to monitor the prevalence and the intensity of the various intestinal parasite infections which are known to be a local health problem.

2. Treatment of those infections, which, because of their presence or intensity, can be considered as a health hazard is needed. All cases of $A$. lumbricoides probably should be treated because of the potential danger of migration of the adult worms during other illnesses. There are documented cases where these large worms (adults average $15-20 \mathrm{~cm}$ in length) have caused obstruction of children's bile ducts with fatal consequences [12]. All cases of E. histolytica should be treated because of the danger of tissue invasion. Cases of Giardia should be treated because of their potential health hazard. Light infections of $T$. trichiura are usually not treated unless clinical symptoms justify the need because available drugs are either toxic or not effective in eliminating all worms. Heavy infections of Trichuris, however, should be treated. Treatment should also be considered for infections such as Strongyloides where internal autoinfection is possible. Pinworm, tapeworm, and moderate to heavy hookworm infections should also be treated.

3. Continued research is needed to develop or improve better anthelmintics. A broad spectrum drug which will simultaneously eliminate a large percentage of the infections with roundworm, hookworm, whipworm, and pinworm is needed.

4. Improvement of the living conditions and educational levels of those disadvantaged individuals living in the lower socioeconomic strata of our society is also required.

\section{Summary}

A survey of intestinal helminths and protozoa was conducted on 887 5-year-old Negro kindergarten children from New Orleans public schools. Thirty-one percent were found to be infected with one or more species of parasites; recommendations for the control and eradication of intestinal parasites in the United States are submitted.

\section{References and Notes}

1. American Public Health Association: Control of Communicable Diseases in Man (American Public Heal:h Association, New York, 1970).

2. Beavfr, P. C.: Quantitative hookworm diagnosis by direct smear. J. Parestol., 35: 125 (1949).

3. BEAver, P. C.: The standardization of fecal smears for cstimation of egg production and worm burden. J. Parasitol., 36: 451 (1950).

4. Center for Disease Control: United States Department of Health, Education and Welfare, Atlanta, Georg:a. Wcekly Morbidity and Mortality Report, 19(47): 455 (1970).

5. Cervoni, W. A., Oliver-Gonzales, J., Kaye, S., and Slomka, M. B.: Dichlorvos as a single dose intestinal anthelmintic for man. Amer. J. Trop. Med. Hyg., 18: 912 (1969).

6. Chandler, A. C.: Introduction to Parasitology (John Wiley \& Sons, Inc., New York, 1955).

7. Colombian Ministry of Public Health: Intestinal Parasitism in Colombia (National Morbidity Investigation, Ministry of Health and Association of Melical Faculties, Bogata, Colombia, 1969).

8. Cort, W. W., Otro, G. F., And Sprndrer, L. A.: Invesigations of Ascaris lumbricoides and the associated intestinal he'minths of man in southwestern Virginia. Amer. J. Hyg., 11: 1 (1930). 
9. Craig, C. F.: A Manual of the Parasitic Protozoa of Man (Lippincott Co., Philadelphia, 1926).

10. Faust, E. C., and Headless, W. H.: Intestinal parasite infections of the ambulatory white clinic population of New Orleans. Amer. J. Trop. Med., 16: 25 (1936).

11. Faust, E. C.: Is there an intestinal parasite problem in college students? J.-Lancet, 62: 260 (1942).

12. Faust, E. C., Beaver, P. C., and Jung, R. C.: Animal Agents and Vectors of Human Disease (Lea and Febiger, Philadelphia, 1968).

13. Hood, M. W.: Previously unpublished data. Department of Pathology, Charity Hospital, New Orleans, Louisiana.

14. Keller, A. E., Leathers, W. S., and Bishop, E. L.: A statewide study of human intestinal helminths in Tennessee. J. Prev. Med., 6: 161 (1932).

15. Keller, A. E., and Leathers, W. S.: The incidence and distribution of Ascaris lumbricoides, Trichuris trichiura, $H y$ menolepis nana and Hymenolepis diminuta in thirty-six counties in Kenutcky. Amer. J. Hyg., 23: 216 (1936).

16. Keller, A. E., Leathers, W. S., and Knox, J. C.: The incidence and distribution of Ascaris lumbricoides, Trichocephalus trichiura, Hymenolepis nana, Enterobius vermicularis, and Hymenolepis diminuta in seventy counties in North Carolina. Amer. J. Hyg., 27: 258 (1938).

17. Kotcher, E., Mario-Miranda, G., Rodrigo-Esquivel, R., PenaChavarria, A., Donohugh, D. L., Caesar-Baldizon, L., AlBERTo-Acosta, G., AND LeON-APUY, J.: Intestinal malabsorption and helminthic and protozoan infections of the small intestine. Gastroenterology, 50: 366 (1966).

18. Lease, E. J., Lauter, F. H., And Dudly, B. W.: Intestinal parasitism and nutritional status-a preliminary report. J. S. C. Med. Ass., 65: 63 (1969).

19. Litrie, M. D.: A Review of Intestinal Parasite Surveys Made in the United States. Seminar, Parasitology Department, Tulane University Medical School, New Orleans, Louisiana, 1959.

20. Maldonado, J. F.: An evaluation of the standard direct smear for egg counting in parasitological work. Amer. J. Trop. Med. Hyg., 5: 888 (1956).

21. Martin, L. K.: Hookworm in Georgia. Amer. J. Trop. Med. Hyg., 21: 919 (1972).

22. Martin, L. M.: Practical and theoretical considerations in the quantitative diagnosis of intestinal helminths by direct smear and dilution methods. Master Thesis, Department of Parasitology, Tulane University School of Public Health and Tropical Medicine, New Orleans, Louisiana, 1964.

23. Moore, G. T., Cross, W. M., McGuire, D., Mollohon, C. S., Gleason, N. N., Healy, G. R., and Newton, L. H.: Epidemic giardiasis at a ski resort. N. Engl. J. Med., 281: 402 (1969).

24. Morgan, P. M., Hubbard, D. W., Willis, R. A., Unglaub, W. G., Langham, P. A., Hedmeg, A. W., and Muldrex, J. E.: Intestinal parasitism and nutritional status in Louisiana. J. La. State Med. Soc., 124: 197 (1972).

25. Moss, E. S.: Incidence of intestinal parasites: analysis of 2,265 routine consecutive stool examinations in out-patient dispensaries of the Charity Hospital of New Orleans, Louisiana. Amer. J. Clin. Pathol., 9: 437 (1939).

26. NNochrRI, E.: Parasitic Disease and Urbanization in a Developing Community (Oxford Press, New York, 1969).

27. Nutritionists are Battling Stomach Worm in South Carolina

Copyright $(1974$ International Pediatric Research Foundation, Inc.
(Times-Picayune National Service, New Orleans, August 8, 1971).

28. Otto, G. F., AND Cort, W. W.: The distribution and epidemiology of human ascariasis in the United States. Amer. J. Hyg., 19: 657 (1934).

29. Otto, G. F., Cort, W. W., And Keller, A. E.: Environmental studies of families in Tennessee infected with Ascaris, Trichuris and hookworm. Amer. J. Hyg., 14: 156 (1931).

30. Owen, G. M., Garry, P. J., Kram, K. M., Nelsen, C. E., and Montalvo, J. M.: Nutritional status of Mississippi preschool children. Amer. J. Clin. Nutr., 22: 1444 (1969).

31. Pena-Chavarria, A., Swartzwelder, J. C., Villaarejos, V. M., Kotcher, E., ANd Arguedos, J.: Dichlorvos, an effective broad spectrum antihelminthic. Amer. J. Trop. Med. Hyg., 18: 907 (1969).

32. Pena-Chavarria, A., Swartzwelder, J. C., Villarejos, V. M., AND ZeLEDon, R.: Mebendazole, an effective broad spectrum anthelminthic. Amer. J. Trop. Med. Hyg., 22: 592 (1973).

33. Schaefer, A. E., And Johnson, O. C.: Are we well fed? The search for an answer. Nutr. Today, 4: 2 (1969).

34. Sulzer, J. L.: Children found to be Anemic: Report to the American Association for the Advancement of Science. (TimesPicayune, New Orleans, May 31, 1970).

35. Swartzwelder, J. C.: A survey of the intestinal parasites of medical students. J. Parasitol., 24: 522 (1938).

36. Unglaub, W. G.: Preliminary Report of the National Nutrition Survey in Louisiana. Hearings on Nutrition and Human Needs, Part 3 (United States Senate Select Committee on Nutrition and Human Needs, The National Nutrition Survey, 91st Congress, Washington, D. C., January 1969).

37. United States Senate Select Committee on Nutrition and Human Needs: Hearings on Nutrition and Human Needs, Part 4 (South Carolina, 91 st Congress, Washington, D. C., February 1969).

38. World Health Organization: Control of Soil Transmitted Helminths (Public Health Papers No. 10, World Health Organization, Geneva, 1961).

39. Yokogawa, M.: The Control of Ascariasis in Japan (H. D. Srivastava Commemorative Volume, Department of Parasitology, School of Medicine, Chiba University, Chiba, Japan, 1970).

40. The parent or guardian of each child involved in this study signed a written consent form allowing the child to participate. This is in conformance with the Declaration of Helsinki.

4I. This research was supported by the Office of Economic Opportunity Contract no. CG 9937 A \& B and the National Institute of Arthritis and Metabolic Disease Traineeship Grant no. 1 T0 1 AM05631-01.

42. The present address of Dr. P. M. Morgan is: Oklahoma State Department of Health, 3400 N. Eastern Ave., Oklahoma City, Okla., 73105 (USA).

43. Dr. W. G. Unglaub is deceased.

44. The present address of Dr. R. A. Willis is: Nutrition Section, Department of Home Economics, University of Texas, Austin, Tex., 78758 (USA).

45. The present address of Dr. D. W. Hubbard is: Nutrition Department, College of Home Economics, University of Tennessee, Knoxville, Tenn. 37916 (USA). To whom requests for reprints should be addressed.

46. Accepted for publication February 1, 1974. 